\title{
THE STRUCTURAL BEHAVIOUR OF COMPOSITE CONNECTIONS WITH STEEL BEAMS AND PRECAST HOLLOW CORE SLABS
}

\author{
Feng Fu \\ Structural Engineer, WSP Group, WSP House, 70 Chancery Lane London WC2A 1AF \\ E-mail: cenffu@yahoo.co.uk
}

Received: 19 November 2007; Revised: 5 January 2008; Accepted: 16 January 2008

\begin{abstract}
The use of composite precast hollowcore floor system has been rapidly increased in U.K. and the international construction market due to its various advantages. However, this composite system is mainly used as simply supported beam, without considering the moment behaviour of the connections. Therefore, little research on the composite joint behaviour of this connection has been conducted so far. In this paper, using the general purpose finite element software ABAQUS, a three dimensional model of the composite joint was set up to simulate the semi-rigid composite beam-column connections of the composite beams with precast hollowcore slabs. Using the proposed model, the numerical studies using 3-D Finite element modelling techniques were carried out. Against with the full scale test results of the author, the structural behaviour of this type of connections was studied.
\end{abstract}

Keywords: Connection; semi-rigid; finite element; connection; modelling

\section{INTRODUCTION}

In the building construction, precast hollowcore slab is a newly developed floor system with limited research. Compared with the traditional composite floor system like the solid slabs or metal profiled decking floor system, it saves construction time; reduce the cost of concrete casting, etc. Therefore, it becomes more and more popular in the construction market. In the construction practice, the composite beams with precast slabs are used as simply supported beam; no moment capacity of the connection has been taken into account in the current design. However research by the author found that even with simple steel beam to column connection, if the longitudinal steel bars are placed around the columns edge, the connection can achieve some moment capacity due to the composite action between the precast slabs and the steel beams. The behaviour of this type of connections more or less can be classified as semi-rigid connections which can be used to enhance the whole stability of the frames. Therefore, the research on the behaviour of this type of connections is quite necessary.

Johnson et al. [1] firstly conducted five tests on composite connections which covered the whole range of the web slenderness available in universal beams and showed that negative moment with semi-rigid joints had greater resistance to bucking and much greater rotation capacity than rigid joints. MacGinley et al. [2] tested a series of bare steel joints and two composite connections. The two composite connections exhibited considerably more capacity than the bare steel joints. Davison et al. [3] tested eleven composite beam-to-columns connections. This was the first study in the U.K. to use relatively flexible joint details to exploit the composite floor action in composite frames. This also was the first attempt to use profiled metal decking rather than a solid slab. The test results suggested that it was unwise to rely solely on mesh to provide tensile reinforcement and that the anchorage of the reinforcement is particularly important. Seven bare steel beam-to-column equivalent joints were tested, the comparison between the two types of connection showed that the composite connection had significant improvement on the stiffness and strength. Anderson et al. [4] carried out research on flush and extended endplate composite connections with metal decking flooring at the University of Warwick. The tests were of a cruciform configuration with the loads being applied at the assumed point of contra-flexure of the beam. Xiao et al. [5] carried out tests on 
flush and partial depth end plate connections with metal decking slab at the University of Nottingham. Twelve tests were carried out on major axis connections using flush end plates of 10 mm thickness with modest amounts of slab reinforcement. A further twelve tests were carried out on fin-plate, partial depth endplate and cleated connections. The rotation capacity found from the experiment was similar to the tests carried out by Anderson et al. [4]

In addition to full scale test, finite element modelling technique is used to study the behaviour of the composite connections. Krishnamurthy et al. [6] modelled the connections by adopting the eight-node sub-parametric bricks in order to reproduce the behaviour of bolted end plate connections. Ayoub et al. [7] used the inelastic beam element for the analysis of steel-concrete composite girders with partial composite action under monotonic and cyclic loads. Sebastian et al. [8] developed a beam element with layered steel beam and layered concrete slab for the analysis of steel-concrete composite girders. In their study, they also included the modelling of profiled steel sheeting. A stub element with an empirical nonlinear shear force-slip relationship is used at the concrete slab-steel beam interface to permit the modelling of either full or partial shear connector action. Baskar et al. [9] built a 3-D FE model using ABAQUS to analyze the steel-concrete composite plate girders under negative bending and shear loading. In order to overcome the convergence problem of under the negative bending, different material models have been tried. The material model adopted is the CAST IRON MODEL and ELASTIC-PLASTIC MODEL. Ahmed et al. [10] proposed a 2-D model for the analysis of composite connections and composite frames using ABAQUS. In order to overcome the convergence problem in the concrete slab's simulation, they ignored the concrete slab under negative bending and analyzed the steel beam with multipoint constraint to behave like a composite girder.

Recently, the mechanical model using the component method has become more and more popular for researchers to investigate the behaviour of composite connections. The principle of this method is to divide the connection into a set of mechanically connected components, representing the behaviour of elemental parts. The behaviour of each element is then described by general constitutive relations, either in plane stress or plane strain. And the connection behaviour can be combined together from these separate element relationships by considering force equilibrium and deformation compatibility. This technique has been used by Tschemmemegg [11], Madas [12] and Rassati et al. [13] in their research.

Although tremendous research has been conducted toward the semi-rigid composite connections, few of them were focused on the composite connection with precast hollowcore slabs. Therefore, the behaviour of this type of connection is still unclear. In this paper, through the full scale tests and 3-D finite element modelling, the behaviour of this type of connections has been studied extensively.

\section{EXPERIMENTAL STUDIES}

In order to study the behaviour of the composite connection with precast hollow core slabs, eight full scale flush endplate composite joint tests with precast hollowcore slabs were conducted by Fu et al. [14]. The variables are stud spacing, degree of the shear connections, area of the longitudinal reinforcement and slab thickness. All specimens were of cruciform arrangement as shown in Fig. 1 to simulate the internal beam-column joints in a semi-rigid composite frame. The specimens were assembled from two $3300 \mathrm{~mm}$ long $457 \times 191 \times 89 \mathrm{~kg} / \mathrm{m}$; grade $\mathrm{S} 275$ universal beams and one $254 \times 254 \times 167 \mathrm{~kg} / \mathrm{m}$ grade S275 universal column to form the cruciform arrangement. The beams are connected to the column flanges using $10 \mathrm{~mm}$ thick flush end plates with two rows of M20 Grade 8.8 bolts. The steel connection is a typical connection currently used in UK practice for 
simple joints. A single row of $19 \mathrm{~mm}$ diameter headed shear studs are pre-welded to the top flange of the steel beams. Finally, two $305 \times 102 \times 28 \mathrm{~kg} / \mathrm{m}$ universal beams were connected to the column web to make up of the full joint arrangement. Heavy columns were used in the tests, and the flange is very thick to ensure no plastic deformation is observed in the column. Full details of the test set up, instrumentation and material are described in the reference Fu et al. [14].

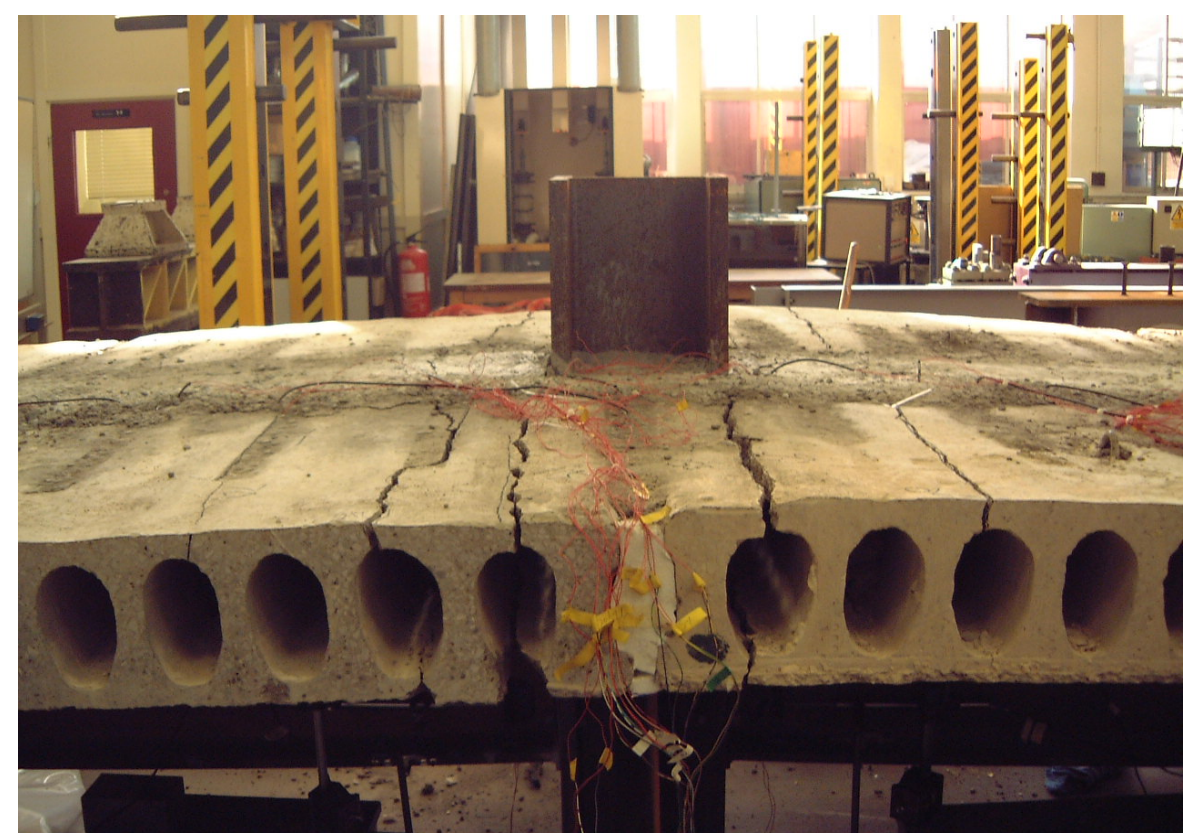

Figure 1. Full Scale Tests

\section{THREE-DIMENSIONAL FINITE ELEMENT MODEL}

Apart from full scale tests, a three-dimensional finite element model consisting of three-dimensional continuum (solid) elements was created by Fu et al. [15] as shown in Fig.2 to simulate the composite joints with precast hollowcore slabs. The general-purpose finite element package ABAQUS [16] is used for the simulation.

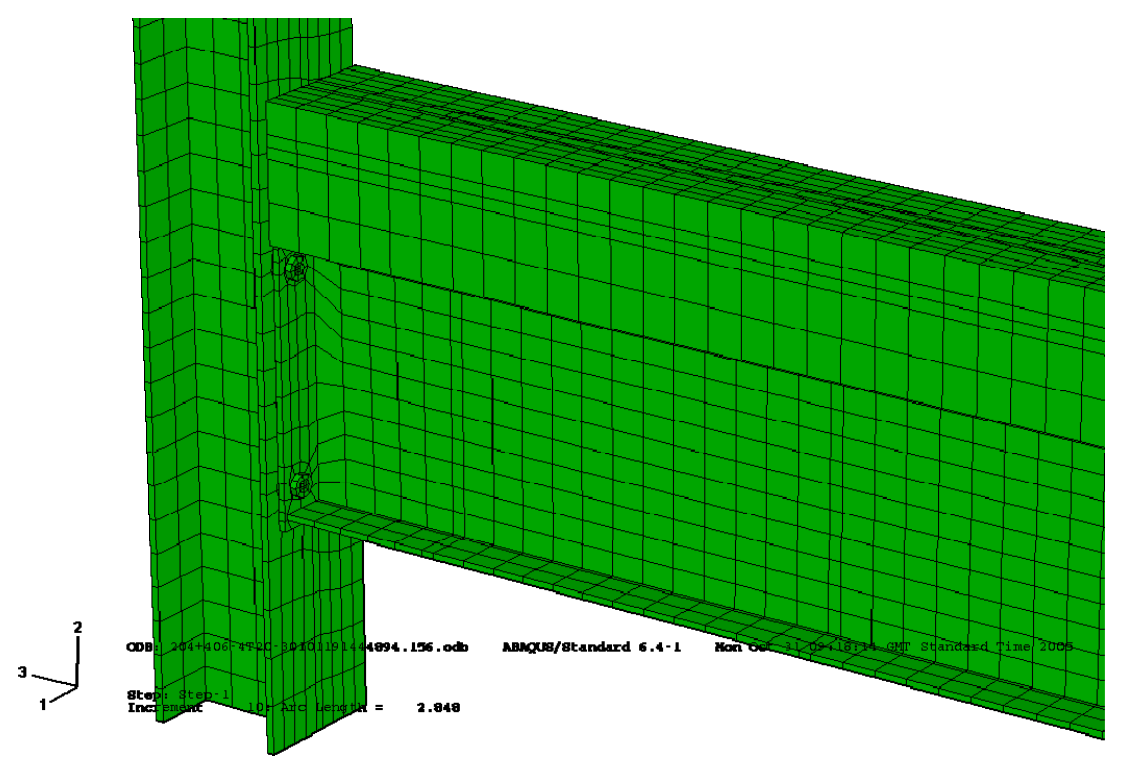

Figure 2. 3-D Finite Element Model 
Using 3-D solid elements, the model replicates the composite joints from the experimental program by $\mathrm{Fu}$ et al. [14]. In order to reduce the computing time of the computer, only one side of the tests was simulated. The sizes of all the components except the hollowcore slabs were closely modelled as the actual experimental work.

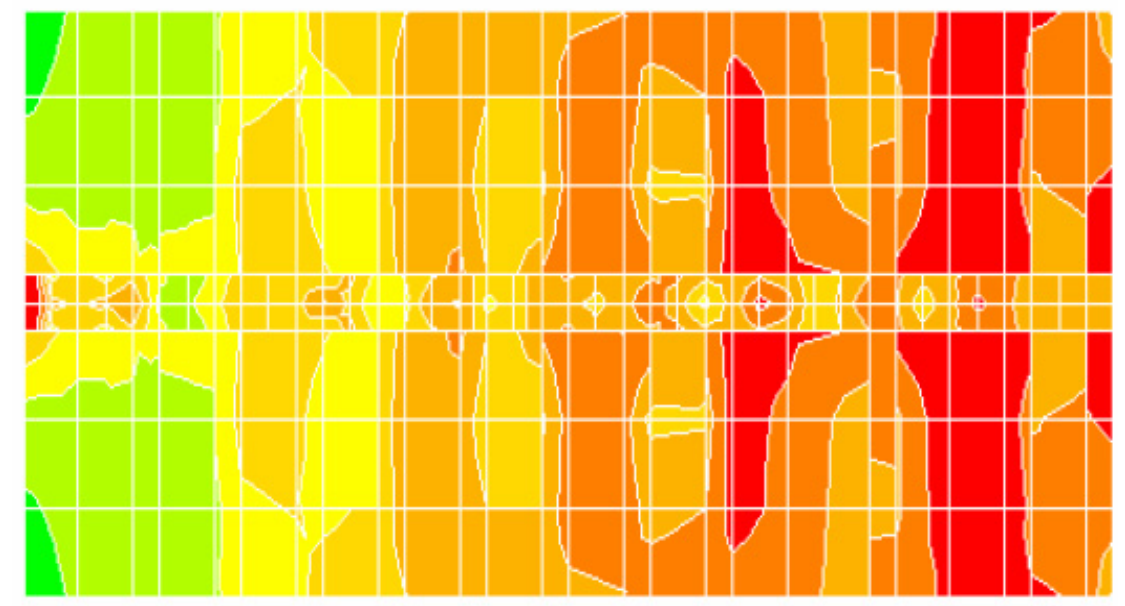

Figure 3. Effective Width of Composite Beam Using Precast Slab

The research conducted by El-Lobody et al. [17] showed that the effective breadth around the joint is confined to the in-situ infill concrete portion of the slabs as it is shown in Fig.3. Therefore, for the slab, only the in-situ infill concrete in the centre is modelled. The boundary conditions and method of loading adopted in the finite element analysis follow closely those used in the tests. Rather than use the smeared reinforcement slab model, the rebar were modelled using 3-d solid element with contact element between the rebar surface and the slab. Material non-linearity was included in the finite element model by specifying a stress-strain curve in terms of the true values of stress and plastic strain. All the structural steel components such as steel beams, steel columns, studs and bolts are modelled as an elastic-plastic material in both tension and compression. The stress-strains relationship in compression and tension are based on the coupon tests result conducted by Fu et al. [14]. A simplified elastic-plastic material model was adopted to simulate the concrete slabs. It is assumed that the concrete behaves as a linear-elastic material up to the yield. The option *PLASTIC is used to specify the plastic part of the material model that use the Von Mises yield surface. For the elastic part of the stress-strain curve, the value of the Young's modulus and the Poisson's ratio of the concrete are determined in accordance to BS8110 [18]. For the plastic part, two different values are adopted in different area of the slab. The main area of the concrete slab as shown is defined with the ultimate tensile stress $f_{t}$ which is obtained from the concrete indirect tensile test. The area with $4 \times \mathrm{d}$ length and $1.5 \mathrm{~d}$ width and the same height of the stud in the compressive side of the stud is defined with the yield stress $0.8 \mathrm{f}_{\mathrm{cu}}$ which is obtained from concrete cube tests. In the hogging moment regions, the concrete slab is mainly under tension. However, for the area around the front of the shear studs, the ultimate compressive strain $\varepsilon_{\mathrm{cu}}$ is given as $0.002 \varepsilon$. Although the proposed material model for the concrete can not predict the explicitly crack initiation and the evolution, the modelling result shows that it is sufficiently accurate for simulating the behaviour of the composite connection. The model has been validated against the full scale tests of Fu et al. [14], as shown in Fig.4, good agreement has been obtained. 


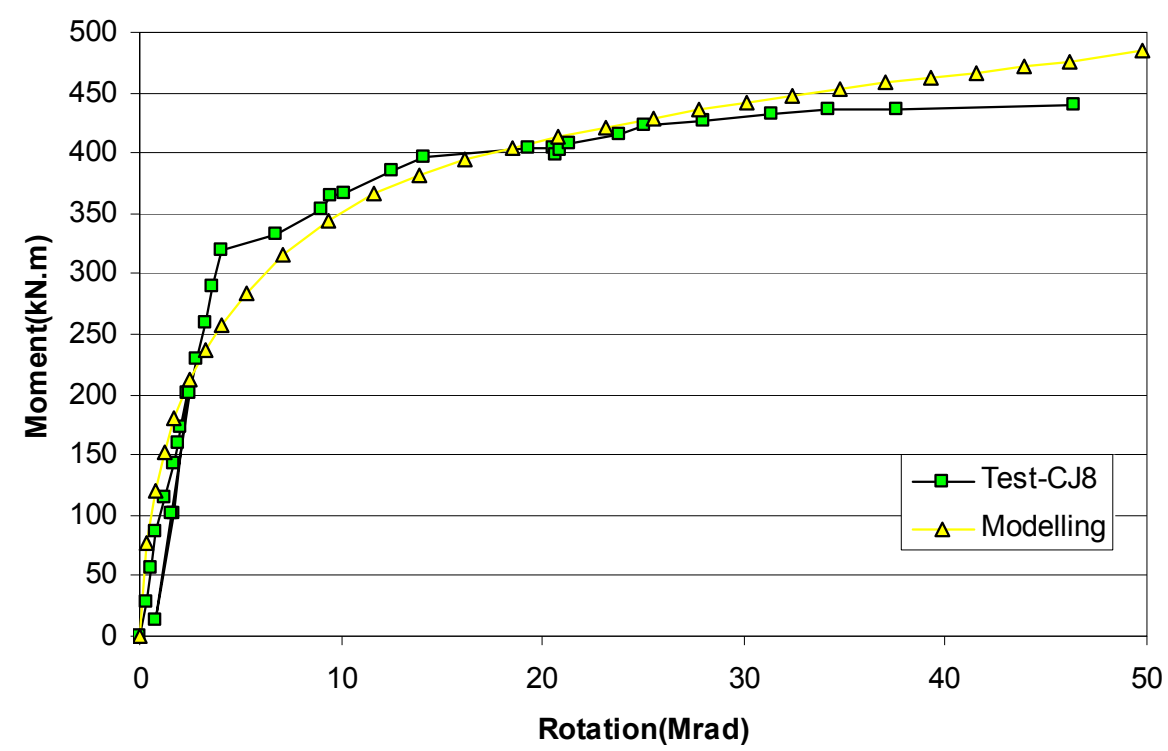

Figure 4. Moment vs. Rotation Curves for Test CJ8 and FE-solution

\section{THE STRUCTURAL BEHAVIOUR OF THE CONNECTIONS}

Using the results of full scale tests of Fu et al. [14] and the proposed 3-D FE model, the parametric study has been conducted. The main variables are first stud spacing, bottom flange thickness and the column sizes etc. Base on the full scale tests result and parametric study of the proposed 3-D model the structural behaviour of the connection is studied as follows:

\subsection{Effect of the Amount of Longitudinal Bars}

Fig. 5 compares the moment-rotation curves of tests CJ2, CJ6, and CJ7 of Fu et al. [14]. All three tests have full shear connections with the same slab thickness except the longitudinal bars were $2 \mathrm{~T} 20,4 \mathrm{~T} 16$ and $2 \mathrm{~T} 16$ respectively. It can be observed from the curves that the rotation stiffness was enhanced with an increase in longitudinal reinforcement. It showed that increases in the amount of longitudinal reinforcement leads to higher moment and rotation capacity.

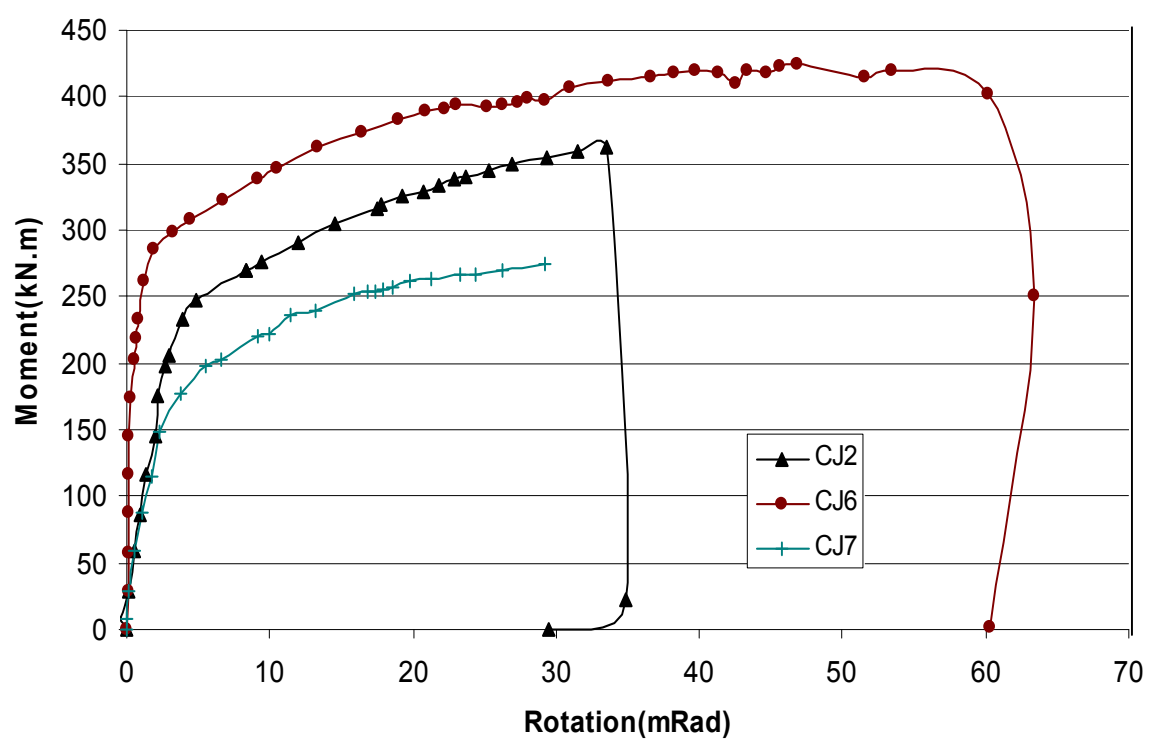

Figure 5. Comparison of Moment-rotation Curves of Tests CJ1, CJ2 and CJ7 


\subsection{Effect of Precast Slab Thickness}

In order to investigate the effective of the slab thickness, two 3-D finite element models CJ8-400 and CJ8-150 were built, these two models are similar to full scale test CJ8 of Fu et al [14], with the slab thickness of $400 \mathrm{~mm}$ and $150 \mathrm{~mm}$ respectively. Fig. 6 is the comparison of the moment rotation relationship of these two models with test CJ8 of Fu et al [14]. Results show that by using a deeper slab, moment capacity was increased, but purely due to an increase in the lever arm, this being accompanied a slight reduction in the rotation capacity.

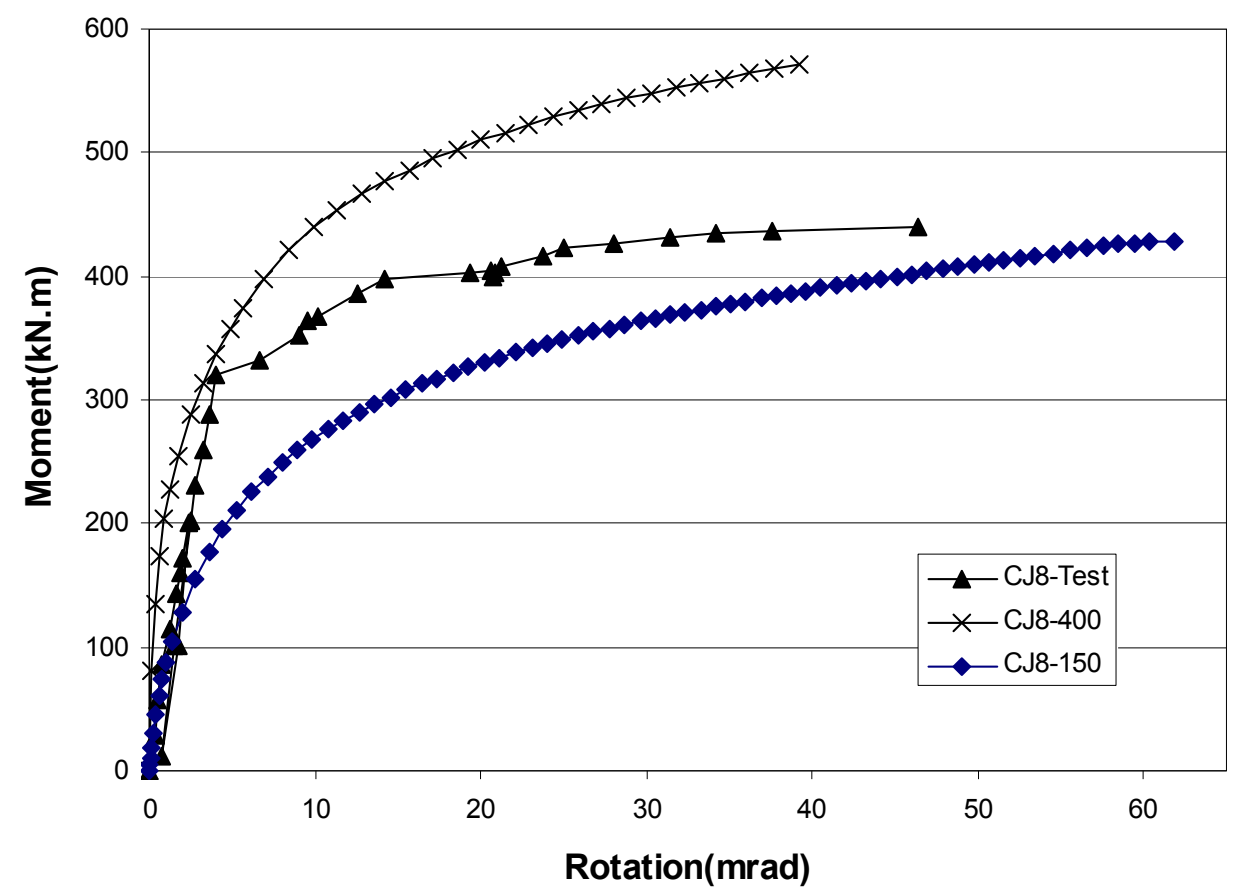

Figure 6. Comparison of Moment Rotation Relationship with Different Slab Thickness

\subsection{Effect of Stud Spacing and Stud Number}

Fig 7 is the comparison of moment-rotation curves of Tests CJ1 and CJ2 of Fu et al. [14].Test CJ1 and CJ2 are identical except that number of the studs is 7 and 4 respectively and with different stud spacing. They are both full shear connection tests. From the comparison of the moment-rotation curves of tests CJ1 and CJ2 (as shown in Fig.7), it can be seen that, although different stud spacing and numbers of stud were used, as both tests were full shear connection, no distinct difference of moment and rotation capacity was found from the test results. The only difference was the rotation stiffness of the composite connection. Test CJ1 has larger rotation stiffness than $\mathrm{CJ} 2$, as more shear studs were used. Therefore, it can be concluded that for full shear connection, the studs number and spacing does not has much influence on the moment capacity and rotation capacity of the connection. It can be also concluded that under the same conditions, the more studs, the larger the rotation stiffness of the connection. 


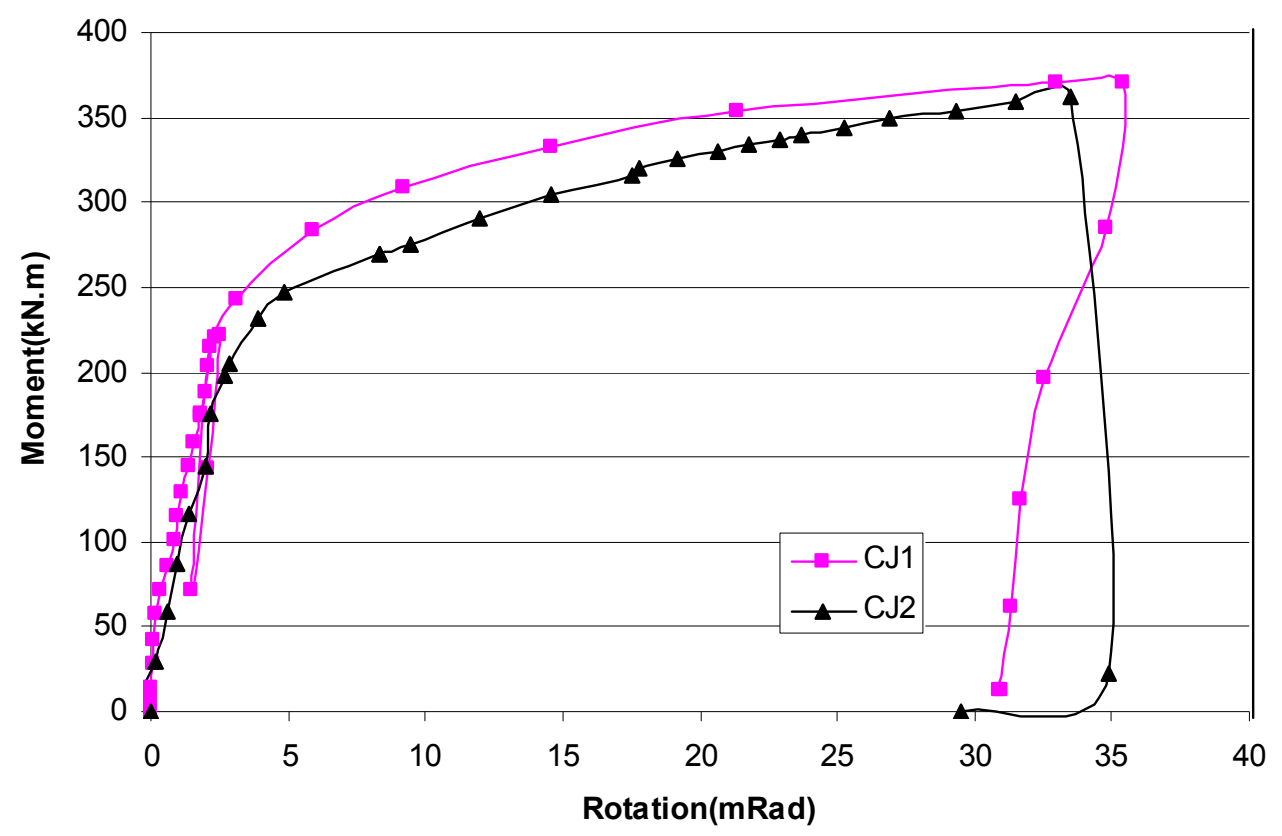

Fig 7 Comparison of moment-rotation curves of Tests CJ1 and CJ2

\subsection{Effect of Column Sizes}

In the actual design practice, yielding of the column flange and buckling of the column web could occur if smaller column sizes were used. In order to further study the behaviour of composite joints, different sizes of column were chosen in the finite element models for the parametric studies. Three 3 -D finite element models with the column sizes of $254 \times 254 \times 167$ UC, $203 \times 203 \times 86$ UC and 203 $\times 203 \times 46$ UC were chosen for the parametric study, where model $254 \times 254 \times 167$ UC replicated the test CJ2 of the full-scale test of Fu et al. [14]. The three models have column web thicknesses of $19.2 \mathrm{~mm}, 12.7 \mathrm{~mm}$ and $7.2 \mathrm{~mm}$ with the flange thickness of $31.7 \mathrm{~mm}, 20.5 \mathrm{~mm} 11 \mathrm{~mm}$, respectively, $457 \times 191 \times 89$ UB beams were used throughout. All other conditions were kept the same as the full scale tests of Fu et al. [14]. The modelling results are shown in Fig.10 and Table 1. It can be seen that the moment-rotation curves for model $254 \times 254 \times 167 \mathrm{UC}$ and model $203 \times 203 \times 46 \mathrm{UC}$ are similar, with slightly higher rotation capacity for model $254 \times 254 \times 167$ UC. With the column sizes decreases to $203 \times 203 \times 46 \mathrm{UC}$, it can be seen that the rotation stiffness decreases with an increases in rotation capacity. The failure modes of all three models are the longitudinal bar failure. As shown in Table 1 , for model $254 \times 254 \times 167 \mathrm{UC}$, due to the heavy column used, the maximum stresses for the column web and flange are only $88 \mathrm{~N} / \mathrm{mm}^{2}$ and $101.6 \mathrm{~N} / \mathrm{mm}^{2}$ respectively. For the other two models, it can be seen that the columns are about to yield. Figure 8 and 9 show the models of UC $203 \times 203 \times 86$ and UC203 $\times 203 \times 46$ at their failure state respectively. It can be seen that the deformation of the column in UC203 $\times 203 \times 46$ is obviously larger than UC203×203 $\times 86$ due to the smaller column size. The maximum stress in the web occurred at the position near the bottom flange of the beam, the assumed centre of the rotation. Also, the rotation of the UC203×203×46 is much greater due to the deformation of the column. For UC $254 \times 254 \times 167$, as heavy column is used, the stress of the column is very small and remains elastic, as was observed in the tests.

It can be concluded that as long as heavy columns are used, the connection can achieve a certain amount of moment capacity and rotation capacity without much difference. Smaller column size will cause higher rotation capacity and lower rotation stiffness. 

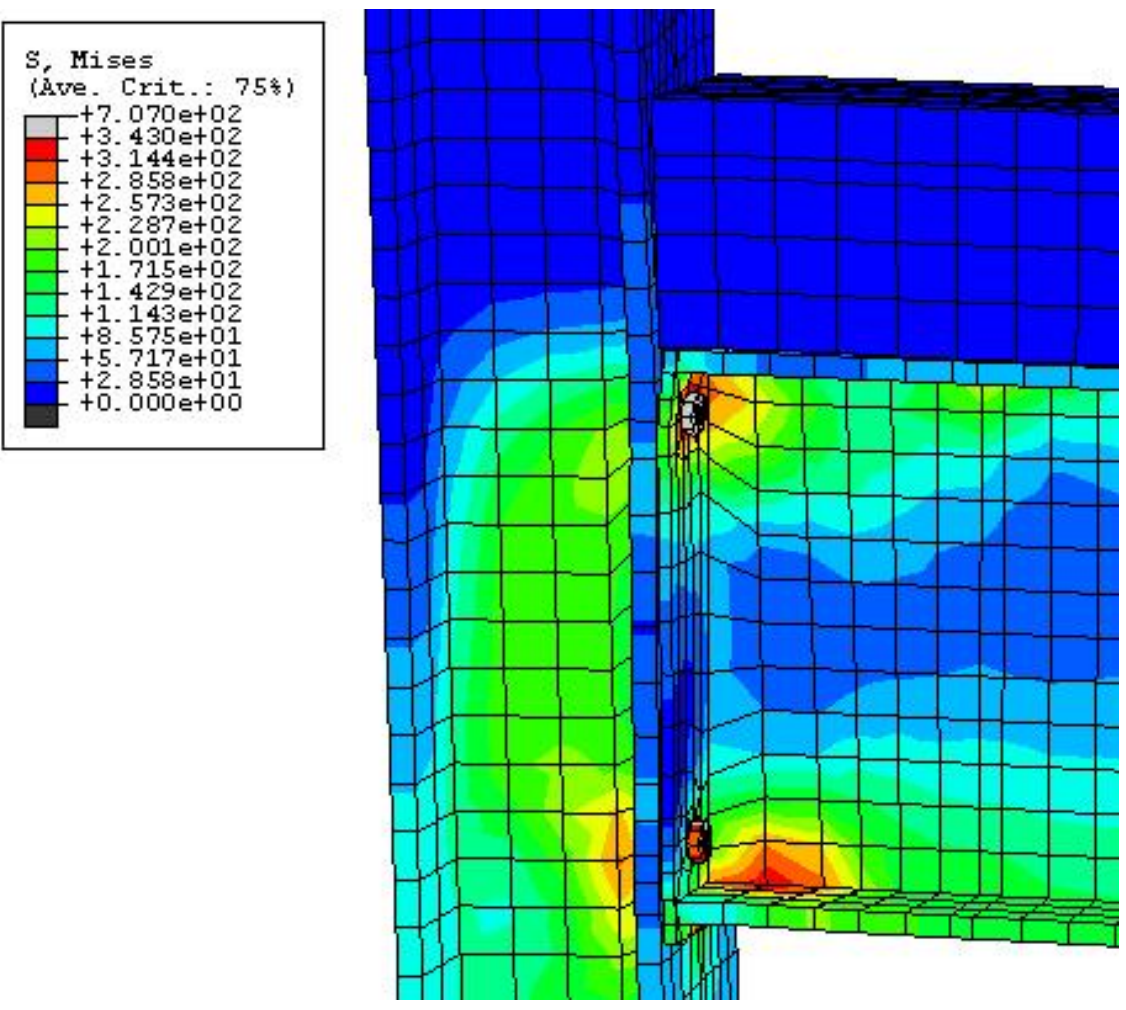

Figure 8 . UC203×203×86 at Failure (Longitudinal Bar Failure)

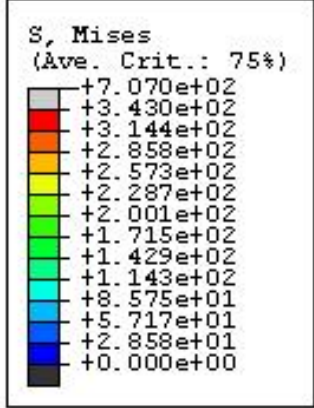

2

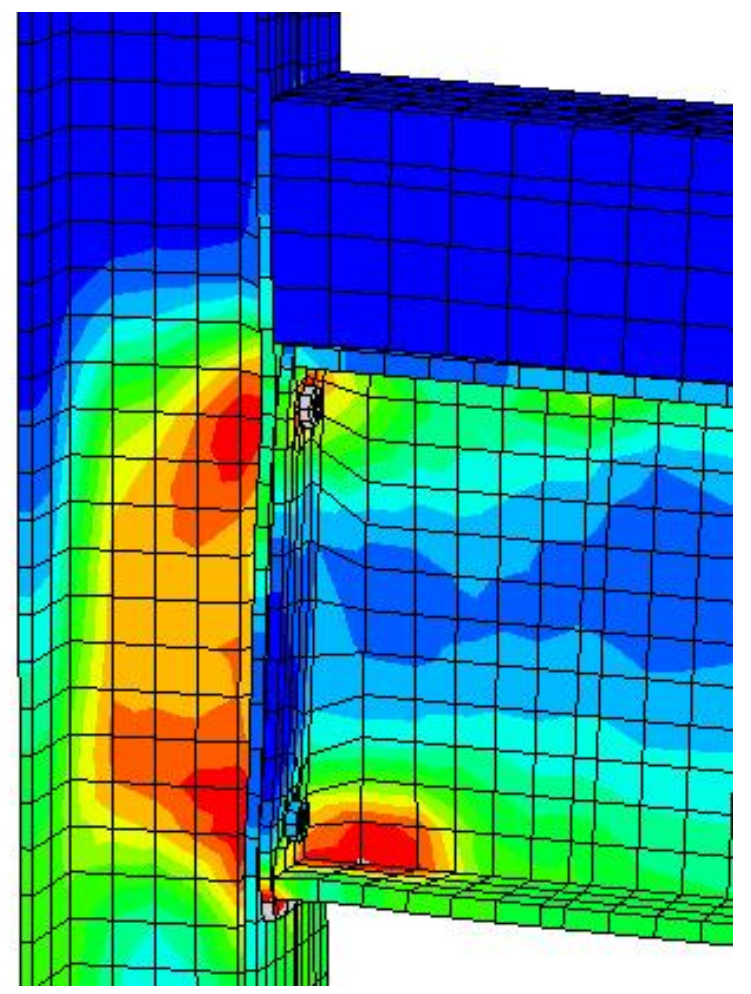

Figure 9. UC203×203×46 at Failure (Longitudinal Bar Failure) 


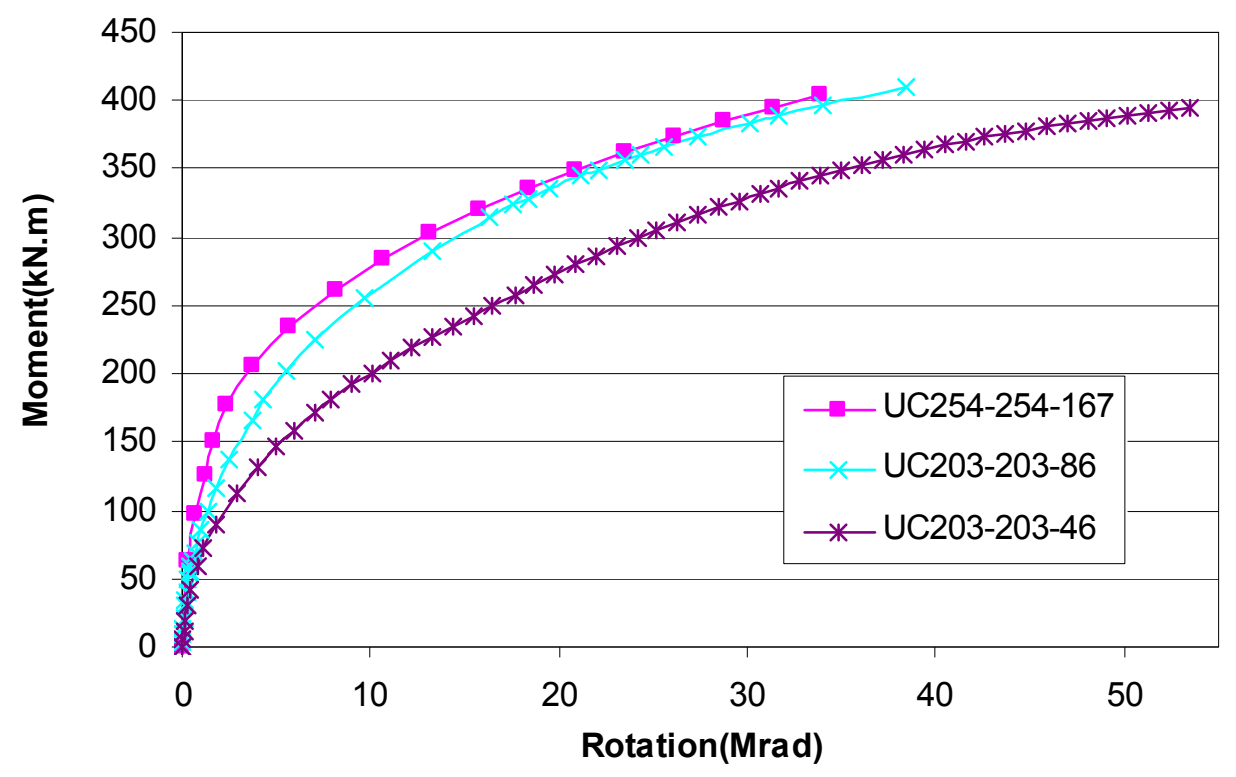

Figure 10. Variation of Moment-rotation Curves with Different Size of the Column

Table 1. Modelling Result

\begin{tabular}{|c|c|c|c|c|c|}
\hline & $\begin{array}{c}\text { Moment } \\
(\mathrm{kN} . \mathrm{m})\end{array}$ & $\begin{array}{c}\text { Rotation } \\
(\mathrm{Mrad})\end{array}$ & $\begin{array}{c}\text { Maximum } \\
\text { column web } \\
\text { stress } \\
(\mathrm{N} / \mathrm{mm} 2)\end{array}$ & $\begin{array}{c}\text { Maximum } \\
\text { column Flange } \\
\text { stress (N/mm2) }\end{array}$ & $\begin{array}{c}\text { Mode of } \\
\text { failure }\end{array}$ \\
\hline $254 \times 254 \times 167 \mathrm{UC}$ & 404 & 34.6 & 88 & 101.6 & rebar \\
\hline $254 \times 254 \times 167 \mathrm{UC}$ & 409 & 38.4 & 303.4 & 248 & rebar \\
\hline $203 \times 203 \times 46 \mathrm{UC}$ & 395 & 53.4 & 343.27 & 304.3 & rebar \\
\hline
\end{tabular}

\section{CONCLUSION}

The behaviour of semi-rigid composite connections with precast hollowcore slabs was examined using full scale tests and 3-D finite element modelling technique, different stud spacing and position, amount of longitudinal bars, column size and precast slab thickness have been examined, following conclusions can be drawn:

1. With full shear connection, increases in the amount of longitudinal reinforcement leads to higher moment and rotation capacity.

2. Using a deeper slab, moment capacity was increased, but purely due to an increase in the lever arm, this being accompanied a slight reduction in the rotation capacity.

3. The stud spacing does not have much influence on the moment capacity and rotation capacity of the connection.

4. Smaller column size will cause higher rotation capacity. However, column flange yielding or web buckling could lead to lower rotation stiffness. 


\section{REFERENCE}

[1] Johnson, R.P. and Hope-Gill, M.C., "Semi-rigid Joints in Composite Frames", International Association for Bridge and Structural Engineering, Ninth Congress, Prelim. Report, Amsterdam, May 1972, pp. 133-44.

[2] MacMackin, P.J. and Cheung, P.A.T., "Flexible Steel and Composite Joint Design", Pacific Structural Steel Conference, Queensland, Australia, 1989, pp. 479-496.

[3] Davison, J.B., Lam, D. and Nethercot, D.A., "Semi-rigid Action of Composite Joints", The Structural Engineer, 1990, Vol. 68, No. 24.

[4] Anderson, D. and Najafi, A.A, "Performance of Composite Connections: Major Axis End Plate Joints", Journal of Constructional Steel Research, 1994, Vol. 31, No. 1, pp. 31-57.

[5] Xiao, Y., Choo, B.S. and Nethercot, D.A., "Composite Connections in Steel and Concrete, I. Experimental Behavior of Composite Beam-Column Connections", Journal of Constructional Steel Research, 1994, Vol. 31, pp. 3-30.

[6] Krisbnamurthy, N. and Graddy, D., "Correlation between 2- and 3-dimensional Finite Element Analysis of Steel Bolted End-plate Connections", Computers and Structures, 1996, Vol. 6, pp. 381-389.

[7] Ayoub, A., and Filippou, F., "Mixed Formulation of Nonlinear Steel-Concrete Composite Beam Element", Journal of Structural Engineering, 2000, Vol. 126, No. 3, pp. 371-381.

[8] Sebastian, W.M. and McConnel, R.E., "Nonlinear FE Analysis of Steel-concrete Composite Structures", Journal of Structural Engineering, 2000, Vol. 126, No. 6, pp. 62-674.

[9] Baskar, K., Shanmugam, N.E. and Thevendran, V. "Finite-element Analysis of Steel-concrete Composite Plate Girder", Journal of Structural Engineering, 1996, Vol. 128, No. 9, pp. 1158-1168.

[10] Ahmed, B. and Nethercot, D.A., "Prediction of Initial Stiffness and Available Rotation Capacity of Major-axis Flush End-plate Connections", Journal of Constructional Steel Research, 1997, Vol. 41, No. 1, pp. 31-60.

[11] Tschemmernegg, F., "On the Nonlinear Behaviour of Joints in Steel Frames, Connections in Steel Structures: Behaviour, Strength and Design”, Elsevier Applied Science Publishers, 1998, London, pp. 158-165.

[12] Madas, P.J., "Advanced Modelling of Composite Frames Subject to Earthquake Loading", Ph.D. Thesis, University of London, 1998.

[13] Rassati, G.A., Leon, R.T. and Noe, S., "Component Modelling of Partially Restrained Composite Joints under Cyclic and Dynamic Loading", Journal of Structural Engineering, 2004, Vol. 130, No. 2.

[14] Fu, F. and Lam, D., "Experimental Study on Semi-Rigid Composite Joints with Steel Beams and Precast Hollowcore Slabs", Journal of Constructional Steel Research, August 2006, Vol. 62, No. 8, pp. 771-782.

[15] Fu, F., Lam, D. and Ye, J.Q., "Parametric Study of Semi-rigid Composite Connections with 3-D Finite Element Approach", Engineering Structures, 2007, Vol. 29, Issue 6, pp. 888-898.

[16] ABAQUS Theory Manual, Version 6.4. Hibbitt, K-arlsson and Sorensen, Inc. Pawtucket, R.I., 2003.

[17] El-Lobody, E. and Lam, D., "Finite Element Analysis of Steel- Concrete Composite Girders", Advances in Structural Engineering, 2003, Vol. 6, No. 4, pp. 267 - 281.

[18] BS 8110, Part 1, "Structural Use of Concrete - Part 1: Code of Practice for Design and Construction, British Standards Institution, London, 1997. 